\title{
Evaluation of some physical and motoric characteristics of athletes with down syndrome
}

\author{
Mehmet Ilkım ${ }^{1}$, Mehmet Özdemir ${ }^{2}$, and Halil Tanır ${ }^{3 a}$ \\ ${ }^{1}$ Physical Education and Sport High School, Inonu University, Turkey. \\ ${ }^{2}$ Physical Education and Sport High School, Bingöl University, Turkey. \\ ${ }^{3}$ Physical Education and Sport High School, Adnan Menderes University, Turkey.
}

\begin{abstract}
The aim of this study was to evaluate some physical and motoric characteristics of Down's syndrome athletes. The sample of the study consists of 60 athletes $(n=30$ experimetal group and $n=30$ control group) who are in the Malatya Sessiz Adımlar Sports Club, aged between 13 and 15 . Athletes in the experimental group were subjected to a training program to improve the balance and flexibility of 2 hours of 3 days a week for 8 weeks. The athletes, in the control group continued their usual training programs. Before and after the 8 -week training program that is applicated for the athletes in the experimental group, the balance and flexibility performances of the athletes in both the experimental and control groups were determined. It was used the flamingo balance test to determine the balance performance of the athletes; was used Sit \& Reach test to determine flexibility performance. In favor of the athletes who are in experimental group a statistically significant difference $(\mathrm{p}<0.05)$ obtained between pre-test and post-test results that is applicated to determine the balance performance from statistical analysis however no statistically significant difference $(\mathrm{p}>0.05)$ obtained between pre-test and post-test results that is applicated to determine the flexibility performance. It was also found that there was no relationship ( $p>0.05$ ) between the BMI values of the athletes and their balance and flexibility performances. In the study, it was found that the training program for 8 week training to improve balance and flexibility that was applied to dealing with athleticism 13-15 age group athletes with down syndrome improved the athletes' balance performance but did not contribute to the their improvement of flexibility performances.
\end{abstract}

Key Words: Down syndrome, balance, flexibilty, BMI

\section{Introduction}

Down syndrome (DS) is one of the most common genetic anomalies that result from chromosome 21 being one more than the normal number (trizomi 21) and which cause mental retardation, immunodeficiency, and congenital heart disease and observed in approximately 700 live births. One of the most common causes of Down syndrome is the problem in the separation of homologous chromosomes in meiosis (nondisjunction).

The non-cleavage event on chromosome 21 occurs largely during oogenesis, and thus the source of abnormal gametes in DS is usually egg cells [1].

\footnotetext{
${ }^{\mathrm{a} C}$ Corresponding author:halil.tanir@adu.edu.tr
} 
When individuals with Down's syndrome are compared [5] with the general population, functional disorders may be seen in motor performance due to differences in cerebellum [4].Children with Down's syndrome can achieve postural control disorders through symmetrical activities. Coordinative skills can be developed with an appropriate therapeutic program. Thus, postural reactions, head, central region, and excretes of control can be provided [9]. Participation in competition-based activity programs for Down's syndrome athletes may contribute to their physical and metabolic development, gaining selfconfidence and social development [3]. For this reason, it is important that the training program to improve the 8-week flexibility and balance performance of the 13-15 year old group who are dealing with athleticism not only can contributes to the development of motor skills in down syndrome individuals but also their the adaptation of daily life.

\section{Methot}

\subsection{Participations}

The sample of the study consists of 60 athletes $(n=30$ experimental group and $n=30$ control group) in the Malatya Sessiz Adimlar Sports Club, aged between 13 and 15, dealing with athleticism. Athletes in the experimental group were subjected to a training program to improve the balance and flexibility of 2 hours of 3 days a week for 8 weeks. The athletes in the control group continued their usual training programs. Before and after the 8 -week training program that is applicated for the athletes in the experimental group, the balance and flexibility performances of the athletes in both the experimental and control groups were determined. The following measurements were made to determine some physical and motoric characteristics of the athletes forming the sample.

\subsection{Anthropometric Measurements}

In the scope of the research, height $(\mathrm{cm})$ and body weight $(\mathrm{kg})$ measurements were performed to determine some anthropometric characteristics of athletes. In length measurements was used FB 721 brand Body Analyzer. Before the measurement, students were asked to remove their shoes, socks and wear clothes that would not weigh as much as possible. During the measurement, students were reminded that they should assemble their heels after taking a deep breath, keep their body in a vertical, keep their head in frankfort position and protect their positions. When body weight $(\mathrm{kg})$ was determined, it was noted that the athletes had to wear their feet naked and there would be clothes that would not weight on them. Measurements were made with Seca 727 digital scales. The body mass index (BMI) values of each athlete were calculated by the weight $(\mathrm{kg}) /$ height length $(\mathrm{m} 2)$ formula from the measurements.

\subsection{Sit \& Reach Test}

The flexibility levels of the athletes were determined by the Sit \& Reach test. During the measurements from the athletes were asked to stretch their bodies as far as possible without twisting their knees over the stand of the Sit \& Reach and remain immobilized at the farthest point they could flex. Better than two measurements were recorded as a test result. 


\subsection{Flamingo Balance Test}

The Flamingo Balance Test was used to determine the static balances of the athletes. According to this test, the athletes; keep in balance by upping with their dominant foot to wooden balance device made of $50 \mathrm{~cm}$. Length, $4 \mathrm{~cm}$. Height and $3 \mathrm{~cm}$. wide. He holds the other foot with the hand on the same side, bending it from the knee, by pulling it towards the hips. When the athlete is in this way balanced with one foot, the time starts and tries to stay balanced for 1 minute. The time is stopped when the balance is disturbed (if he leaves his foot while holding it, falls from the board, touches to ground with anywhere his body and etc.). When the athlete provides his balance again by upping to balance device, time continues from where it left off. The test continues by the way for one minute. When the time is up, the athlete's attempt to provide each balance is calculated and this number is recorded as the athlete's score when one minute is completed at the end of the test.

\section{Findings}

Table 1. Comparison of Balance and Flexibility Performances of Experiment Group

\begin{tabular}{|c|c|c|c|c|c|c|}
\hline \multirow{2}{*}{ Variables } & \multirow{2}{*}{ Tests } & \multirow{2}{*}{$\mathbf{n}$} & \multirow{2}{*}{$\mathbf{X}$} & \multirow{2}{*}{ Ss } & \multicolumn{2}{|c|}{ t Test } \\
\hline & & & & & $\mathbf{t}$ & $\mathbf{p}$ \\
\hline \multirow{2}{*}{ Balance (error) } & Pre test & 30 & 5.43 & 2.55 & \multirow{2}{*}{6.242} & \multirow{2}{*}{$0.000^{*}$} \\
\hline & Post test & 30 & 3.20 & 1.95 & & \\
\hline \multirow{2}{*}{ Flexibilty (cm) } & Pre test & 30 & 5.37 & 3.44 & \multirow{2}{*}{1.769} & \multirow{2}{*}{0.087} \\
\hline & Post test & 30 & 4.37 & 2.82 & & \\
\hline
\end{tabular}

* significiant of level 0.05

It is seen that there is a significant difference between the pre-test and post-test results regarding the balance performance of the athletes in the experiment group $(p<0.05)$. However, it is understood that there is no significant difference between the pre-test and post-test results regarding flexibility performance of athletes $(p>0.05)$.

Table 2. Relationship Between BMI Values and Balance and Flexibility Performances of the Experiment Group

\begin{tabular}{|l|c|c|c|c|}
\hline \multirow{2}{*}{ Variables } & \multicolumn{2}{|c|}{ Balance } & \multicolumn{2}{c|}{ Flexibilty } \\
\cline { 2 - 5 } & $\mathbf{r}$ & $\mathbf{p}$ & $\mathbf{r}$ & $\mathbf{p}$ \\
\hline BMI & 0.130 & 0.494 & 0.074 & 0.699 \\
\hline
\end{tabular}

BMI: BodyMass Index

There is no statistically significant relationship between the BMI values of the athletes in the experimental group and the balance and flexibility performance $(p>0.05)$. 
Table 3. Comparison of Balance and Flexibility Performances of the Control Group

\begin{tabular}{|c|c|c|c|c|c|c|}
\hline \multirow{2}{*}{ Variables } & \multirow{2}{*}{ Tests } & \multirow{2}{*}{$\mathbf{n}$} & \multirow{2}{*}{$\mathbf{X}$} & \multirow{2}{*}{ Ss } & \multicolumn{2}{|c|}{ t Test } \\
\hline & & & & & $\mathbf{t}$ & $\mathbf{p}$ \\
\hline \multirow{2}{*}{ Balance (error) } & Pre test & 30 & 8.70 & 1.98 & \multirow{2}{*}{-0.582} & \multirow{2}{*}{0.486} \\
\hline & Post test & 30 & 8.90 & 2.03 & & \\
\hline \multirow{2}{*}{ Flexibilty (cm) } & Pre test & 30 & 3.13 & 1.77 & \multirow{2}{*}{-0.660} & \multirow{2}{*}{0.514} \\
\hline & Post test & 30 & 3.27 & 1.48 & & \\
\hline
\end{tabular}

It is seen that there is a significant difference in the balance performance of the athletes in the control group when the pre-test and post-test results are compared $(\mathrm{p}<0.05)$.

Table 4. The Relationship Between BKI Values of Control Group and Balance and Flexibility Performances

\begin{tabular}{|l|c|c|c|c|}
\hline \multirow{2}{*}{ Variables } & \multicolumn{2}{|c|}{ Balance } & \multicolumn{2}{c|}{ Flexibilty } \\
\cline { 2 - 5 } & $\mathbf{r}$ & $\mathbf{p}$ & $\mathbf{r}$ & $\mathbf{p}$ \\
\hline BMI & -0.003 & 0.986 & -0.089 & 0.640 \\
\hline
\end{tabular}

BMI: Body Mass Index

There was no statistically significant relationship between the BMI values of the athletes in the control group and their balance and flexibility performances $(p>0.05)$.

\section{Discussion and conclusion}

Individuals with Down's syndrome have weak muscle strength, low muscle tone and poor motor coordination [12]. The difficulties in motor skills can affect the ability of individuals with Down's syndrome to perform various tasks in their daily lives [6]. Furthermore, in children with Down's syndrome and adolescents due to obesity, flatfood [7] and visual and auditory functional disorders can lead to loss of balance [8]. In studies conducted to determine balance control in individuals with Down's syndrome, were found individuals with Down's syndrome to have a weaker balance than healthy subjects, and the likelihood of postural disturbances was higher in these individuals [2] and [10].

In this study, it could said that while the athletes in the experimental group contributed to the development of equilibrium performance, the training they performed to improve balance and flexibility performance for 8 weeks, it didn't not contribute to the development of flexibility performances. When the average values of the athletes' balance and flexibility performances in the control group are examined, it is understood that the athletes in the control group decrease their balance performances after 8 weeks of their usual training. In athletes of the control group, although have been seen improvement of the their flexibility performance after 8 weeks of training, this improvement doesn't mean statistically significant. In this study, it is understood that the BMI values of the athletes in the experimental and control groups did not affect the balance and flexibility performances positively or negatively. 
In the study, it was found that the training program for 8 week training to improve balance and flexibility that was applied to dealing with athleticism 13-15 age group athletes with down syndrome improved the athletes' balance performance but did not contribute to the their improvement of flexibility performances. For this reason, athletes with Down's syndrome who are dealing with Athleticism could provided to participate of them in training programs to improve balance for 8 weeks or longer. Thus, depending on the development of balance performance in athletes with down syndrome, it may contribute to the increase of sportive performance or adaptation process to the daily life.

\section{Referance}

1. Eröz, R., Okur, M., \& Berik, Ö. Down sendromlu çocuklarda AgNOR sayısı ile gelişim arasında bir ilişki var mı?. Düzce Üniversitesi Sağlık Bilimleri Enstitüsü Dergisi, 1(1), 8-11., (2011).

2. Galli, M., Rigoldi, C., Mainardi, L., Tenore, N., Onorati, P., \& Albertini, G. Postural control in patients with Down syndrome. Disability and Rehabilitation, 30(17), 12741278., (2008).

3. Gonzalez-Aguero, A., Vicente-Rodriguez, G., Moreno, L.A., Guerra-Balic, M., Ara, I., \& Casajus, J.A. Health-related physical fitness in children and adolescents with Down syndrome and response to training. Scandinavian Journal of Medicine \& Science in Sports, 20, 716-724., (2010).

4. Lahtinen, U., Rintala, P., \& Malin, A. Physical performance of individuals with intellectual disability: A 30-year follow-up. Adapted Physical Activity Quarterly, 24(2), 125-143., (2007).

5. Latash, L.P., Latash, M.L., \& Meijer, O.G. 30 years later: On the problem of the relation between structure and function in the brain from a contemporary viewpoint (1996) part II. Motor Control, 4(2), 125-149., (2000).

6. Marques-Aleixo, I., Querido, A., Figueiredo, P., Vilas-Boas, J. P., Corredeira, R., Daly, D., \& Fernandes, R. J. Intracyclic velocity variation and arm coordination assessment in swimmers with Down syndrome. Adapted Physical Activity Quarterly, 30(1), 70-84., (2013).

7. Pau, M., Galli, M., Crivellini, M., \& Albertini, G. Foot-ground interaction during upright standing in children with Down syndrome. Research in developmental disabilities, 33(6), 1881-1887., (2012).

8. Pitetti, K., Baynard, T., \& Agiovlasitis, S. Children and adolescents with Down syndrome, physical fitness and physical activity. Journal of Sport and Health Science, 2(1), 47-57., (2013).

9. Popa, C.E. \& Ovidiu, G. (2012). Study regarding the improwement of postural control in children who have down syndrome through swimming, Scientific Journal of Education, Sports, and Health, 2(13), 85-99., (2012).

10. Rigoldi, C., Galli, M., Mainardi, L., Crivellini, M., \& Albertini, G. Postural control in children, teenagers and adults with Down syndrome. Research in developmental disabilities, 32(1), 170-175., (2011).

11.Vuillerme, N., Marin, L., \& Debû, B. Assessment of static postural control in teenagers with Down syndrome. Adapted Physical Activity Quarterly, 18(4), 417-433., (2001).

12. Wu, J., Beerse, M., Ajisafe, T., \& Liang, H. Walking dynamics in preadolescents with and without Down syndrome. Physical therapy, 95(5), 740-749., (2015). 